\title{
Supporting and Inhibiting Factors in the Structured Peer Network among Housewives in Coping with HIV/AIDS
}

\author{
A. Demartoto, R. B. Soemanto, S. Zunariyah \\ Department of Sociology, Faculty of Social and Political Sciences, \\ Sebelas Maret University \\ INDONESIA \\ argyodemartoto@ymail.com
}

\begin{abstract}
HIV/AIDS case in housewives increases over times in Indonesia, but no serious attention is paid to it. This exploratory qualitative research aimed to find out supporting and inhibiting factors in structured peer network model among housewives in coping with HIV/AIDS in Surakarta Indonesia. Data collection was conducted using observation, in-depth interview, Focus Group Discussion, and documentation study techniques. Technique of analyzing data used was an interactive model of analysis. The result of research showed that the reaching strategy using structured peer network started from Ambassador establishing Second Layer, reaching housewives living around, and then in other areas. The local government supported it in the form of licensing and infrastructure, while AIDS Coping Commission of Surakarta city did it by planning and preparing program, selecting prospect ambassador, initial training, reinforcement training, supervision, communication and coordination between stakeholders, and evaluation. The constraints included the difficulty of establishing second layer, reaching individual, peer environment, less optimal communication and coordination, less prepared management of program, so that the role of education was simplified.
\end{abstract}

Keywords: Supporting, Inhibiting Factors, Structured Peer Network, Housewives, HIV/AIDS management.

\section{INTRODUCTION}

As reported by UNAIDS, in 2014, there were 36.9 million people living with HIV and it is estimated that a half of them are women. Regarding HIV in Asia and Pacific, UNAIDS reported in 2013 in Asia 8.2 million people lived with HIV and 2.7 million of them were women. In Indonesia the HIV and AIDS cumulative cases during January 1, 1987-September 30, 2014 consisted of 150,296 HIV and 55,799 AIDS cases. The proportion of AIDS was 29\% among women [1]. Data of Local AIDS Coping Commission of Surakarta City's during October 2005-March 2015 showed 1565 HIV/AIDS cases in Surakarta: 532 HIV, 1,033 AIDS cases and 449 deaths. HIV case, by sex, consisted of $265(49.9 \%)$ women, 267 $(50.1 \%)$ men, while AIDS case $343(32.65 \%)$ women and $710(67.4 \%)$ men. There were 109 housewives with HIV and 131 with AIDS. This medical social condition indicates the incidence of HIV/AIDS epidemic feminization and needs special attention. One attempt of preventing and coping with HIV/AIDS in Surakarta is health behavioral changing intervention to the group with high risk of being infected with HIV/AIDS and the common society by the Field Worker reaching and guiding individuals and group through Peer Education (PE)

HIV/AIDS PE is considered as appropriate process, strategy, dissemination and communication channels for all of society classes, including housewives involving selection, training and support of special group's members to educate the members in peer group on HIV/AIDS, drug and such related topics as gender, sexual relationship and sexuality, thus the members can be motivated to anticipate better the situation with high risk of HIV/ [2].PE is expected to modify social norms and to stimulate collective measure supporting the HIV/AIDS coping policies and programs in wide society [3].Social activity such as HIV/AIDS PE occurs because of repeated creation using instrument enabling them to act as actor rather than social actor. The actor reproduces what occurring repeatedly in the society. Meanwhile, in contrast, an agent reproduces and produces precondition thereby allowing their activity to undertake. In undertaking the activity, human beings always make conceptualization with the knowledge they have. It is this Human Knowledge Ability that becomes foundation of structuring theory [4].

A variety of studies on PE in preventing and coping with HIV/AIDS generally state that PE program contribute positively to improved knowledge, and changing attitude and behavior of targeted groups [5]. Studies on PE with prostitutes and their sexual partner conclude similarly [6] [7] [8] . Nevertheless, the contribution of PE to preventing and coping with HIV/AIDS still face some problems as environment factor readiness and supporting stakeholders [9] [10] [11] .PE program can run smoothly firstly, but then it is discontinued because of limited resource and weak control or overseeing. Center for Development and Population Activities reports that the sustainable development of PE is more effective using Structured Peer Network Model. Recruiting and training peer educator, recruiting, and training peer promoter, and recruiting peer contact and discussing the same thing they have learnt in training. Structured Peer Network model has advantage over other models in which it maintains the long-term program sustainability [12]. This study aimed to find out the supporting and inhibiting factors of structured peer network model among housewives in dealing with HIV/AIDS in Surakarta Indonesia. 


\section{METHODS}

This exploratory qualitative research was conducted in Surakarta Indonesia. Housewives and peers involved in structure peer network to cope with HIV/AIDS in Surakarta were selected with purposive sampling technique. The data consisted of primary data including Surakarta City's Local AIDS Coping Commission, Health Office of Surakarta City, Voluntary Counseling and Testing clinical service, LSM SPEK-HAM concerned with HIV/IDS issue, Solo Plus Peer Support Group, and secondary data. Data collection was conducted using indepth interview, non-participatory observation, documentation and Focus Group Discussion. Technique of analyzing data used was an interactive model of analysis encompassing three components of: data reduction, data display, dan conclusion drawing [13].

\section{RESULT AND DISCUSSION}

PE program in Surakarta has been adjusted when applied to People Caring About AIDS program, in which the housewife peer group network has only two structural layers and targets to be achieved in the second layer limited to 4 persons only. The number of second layer is limited recalling the housewives' dense activities in RT (neighborhood association), RW (citizen's associations), Kelurahan (Administrative village), thereby not allowing the achievement of too high target to recruit the second layer. Some Kelurahans in Surakarta have successfully created second layer effectively. The attempts the peer educator takes to create second layer are to observe the housewives in their own RT area, to look for the housewives with interest in getting involved seriously in AIDS prevention program. Thereafter the peer educating team ( 2 persons) teach the material about AIDS and drug abuse prevention, audience mastery technique, and etc to those selected. Those selected are generally the most proximate familiar housewives. It facilitates the establishment of team, because they have known each other's character. However, some of them are taken from the administrators of RT, RW, and PKK (Family Welfare Empowerment) as they have been accustomed with doing the activity and will be trained more easily than nonadministrators. Some peer educators distribute brochure to housewives to generate the interest in attending AIDS and drug abuse prevention activity. This technique can help obtain the prospect second layer, despite some follow-up required through personal approach. After educator team trains the second layer, all the members of second layer recruited successfully are involved in reaching activities in one's RT/RW or other's.

The establishment of structured peer group network is not easy. The peer educators' experience shows that the reaching in Kelurahan is relatively easy because it is their own environment and acceptable to the familiar peers. The reaching technique in kelurahan implemented by the peer educators includes cooperating with social organizations such as PKK and KarangTaruna (Youth Organization). The material of HIV/AIDS education is inserted into other material in PKK activity, arisan (gathering), and etc. This technique reaches other housewives effectively. Several peer educator groups choose the simpler way, presenting directly before RT's, RW's, and kelurahan's members in discussion format. It is usually held by organizing massive illumination (education). It is intended to learn the material in-depth and to hold debriefing to understand better the material delivered. Other variation in reaching activity is to include games activity.

Some peer educators state that reaching activity in group is easier than that individually because the material presentation can be made in turn corresponding to the material a peer educator mastered mostly. In individual reaching, not all of materials can be delivered because of a peer educator's incomprehensive mastery. However, individually material delivery is considered as better because of informal and intimate situation, meaning that it is not designed in a structured way, thus information can be delivered in housewife language. Reaching activity in group conducted in one way lecturing emphasizes on the completely and correctly material delivery, sometimes added with debriefing session and in the end of presentation post-test is held to evaluate the extent to which the information has been absorbed well by the participants. In conducting reaching activity to other RT, $\mathrm{RW}$, the challenge the peer educator faces are more severe, because they deal with unfamiliar audience and the corresponding administrators of RT, RW, and kelurahan do not accompany them during the education process. It makes the peer educators conduct the education unsuccessfully.

So far, the RT's, RW's, and Kelurahan's responses are good and supporting because of HIV/AIDS and drug abuse issues important to know to the members of community. Nevertheless, only some of those are fully supporting, in the term of formality (licensing for housewives to attend the activity), without material and morale supports. Some RTs, RWs, and Kelurahans have no multimedia and special room for meeting, and the administrators' preoccupation with their activity lead to the limited development of HIV/AIDS and drug abuse issues. KPAD Surakarta's attempt and supportability are considerable and important, by carrying out program management including program planning and preparation. It is indeed not independent of its position as activity organizer contributing to the organization of PE training, overseeing and supervision in the field, coordination and communication with stakeholders, and organizing program since planning stage, prospect ambassador selection, preliminary training, intermediate training, supervision, and evaluation.

Structured peer network model applied to housewives PE activity in People Caring about AIDS program still faces some barriers including: the peer educator's difficulty of creating second layer, less supporting situation, difficulty of allocating time properly to household and education activities, peer educators not equipped with techniques of recruiting and selecting second layer leading to no guidelines of constructing structured peer network model. The barriers the peer educators face often come from peer environment including the peers' less positive attitude, response and interest in the material delivered. Education activity is often distracted by the audiences' less attention and preoccupation with their activity. Another problem is how to maintain motivation and active involvement of second layer in order to contribute as same as the peer educators. The implementation of housewives PE activity in People Caring about AIDS program with a broader scope, some problems arise with program management including less 
optimal program planning and preparation as the similar activity has been conducted frequently. In addition, intensive supervision cannot be conducted because of limited number of facilitators the program organizer has. Those technical barriers indicate the less good communication and coordination between stakeholders.

PE program [14], found such barriers as program input management (time, educators, and fund), difficulty of recruiting educator, individual motivation and capacity not assumable before. The result of research also shows the same phenomenon related to barriers with the application of PE program. In Giddens' view on structuring theory emphasizing on individual relation and structure, structure not only provides constraints (barrier) but also enables. In this context, the housewives PE activity in People Caring about AIDS program in Surakarta is inhibited by the inhibiting structure, but it is also helped by the supporting one. The primary keys to this are peer educator and housewives as the target of program. They should put themselves well, as actor or agent. In structuring perspective, actor is not as same as agent; actor only reproduces the values coming from structure, but agent is capable of reproducing the actions not always coming from such the value.

Peer educators should recognize their role as agent capable of delivering message and information of HIV/AIDS prevention and coping to the housewives formerly unaware of it. For that reason, in recruitment, peer educator should consider whether or not the peer educator they choose can be an agent. Housewives in this case serve as merely actors. For the housewives to reproduce the measures of preventing and coping with HIV/AIDS, certain attempt is required. The intended attempt should be able to touch individual's consciousness.

Technique of recruiting second layer is relatively different in one area from another. The selection of second layer is an intuitive decision, for example, an individual is selected because he is serious, with high interest and willingness, wise and smart, kind, and etc. It impacts on the unclear function of second layer. With the concept of reaching in group rather than in small team, the function of second layer is considered as less effective. An effective reaching activity requires 3 peer educators maximally [3].

The reaching activity in Surakarta is largely accomplished through outreach in group because the ambassadors are not equipped with interpersonal communication skill training needed in reaching the individual. It is different from reaching in group, relying on public speaking skill. Individually reaching activity is not organized as a structured elaboration but unplanned face-to-face dialog. The mastery of interpersonal communication skill is an important element necessary to the successful reaching activity individually. It can apparently prevent most ambassadors from reaching individually, so that it becomes supplement to reaching in group only. Peer educators dealing with their peer's unawareness should improve their intellectuality, knowledge, and experience, to get positive attitude, response, and interest from their peers in the material delivered.

Peer educator training has been packaged in the form of preliminary and reinforcement trainings, corresponding to the concept of PE in general. However, preliminary training is not designed to provide the ambassadors with complete knowledge and skill, but only to introduce HIV/AIDS and drug issues. It affects the ambassadors' ability of serving as peer educators in their own area as concept of preliminary training used is ineffective to equip the ambassadors. Preliminary training should be provided completely and comprehensively to prevent the ambassadors from being inactive and feeling not confident in undertaking reaching activity, thereby increasing the need for supervision from RT's, RW's and Kelurahan's administrators, facilitator or organizer. The preliminary training should include the facts on HIV/AIDS and drugs, behaviors that should be prevented/changed (risky behavior), and participatory technical training that the ambassadors can employ to involve peer group in dialog of solving behavior problem and inhibiting factors such as sexuality, gender, social-economic aspects enclosing HIV/AIDS and drug issues.

The need for supervision is so high that the program organizer should prepare the adequate number of facilitators. Special supervision by program organizer is required to maintain the quality of $\mathrm{PE}$ and to get feedback through direct observation and dialog with ambassadors in the field. The supervision is also required in guiding the ambassadors establishing the second layer, as the key for peer group network to maintain the PE sustainability in long term. The too high expectation of stakeholders indicates that Surakarta City's KPAD as the program organizer does not successfully communicate the program's border, scope, and coverage. Several technical barriers in the field indicate the poor coordination among the stakeholders. Structured peer network model needs coordination and resource integration among the stakeholders, thereby facilitating the implementation and the maintenance of long-term PE program sustainability. So, communication and coordination aspects play important parts in the successful PE program.

The simplification taken in housewives PE activity in People Caring about AIDS program can be seen from some aspects. KPAD as the program organizer has a target of reaching as many as possible audiences through ambassador as peer educator. To achieve the target, the concept of peer educator is simplified in order to be conducted in short time and with less training. When the original concept is used, referring to either UNAIDS or Republic of Indonesia Health Ministry's concept, the PE process will take long time and process, and requires the intensive training before the ambassadors undertake their duty. Considering the practical aspect, the program emphasizes on achieving the quantitative aspect (number of reaches) by simplifying the PE concept itself. The concept of peer educator's role is simplified into that of communicator serving to disseminate information and knowledge among the peers. For that reasons, the standardized presentation material (flip-chart) is prepared, and training of mass communication (public speaking) technique is provided for them. Compared with the universally prevailing PE concept throughout world, the role seems to be very limited. Peer educator actually serves not only as communicator but also: as counselor for the problematic peers, to give referral to the relevant health care center, to help decision making, to build supportive attitude among the People living with HIV/AIDS, to support the peers to maintain behavioral 
change, and etc. Such these roles, of course, do not emphasize on quantity (number of reaches), but on quality of PE itself.

\section{CONCLUSION}

Structured peer network model has distinctive appeal to the organizer of $\mathrm{PE}$ program specifying the high reaching target should be equipped with interpersonal communication skill and the method of discussing HIV/AIDS and drug issues personally with peer and intensive training and supporting supervision are required for the peer educator in charge of establishing the peer group network, to make the second layer (or third layer, and so on) functions as a true peer educator. The government should expand its reach and follow-up PE programs using a local community-based approach.

\section{ACKNOWLEDGEMENT}

The authors want to express their gratitude for any support of their research process to the distinguished: Directorate of Research and Society Services, Directorate General of High Education, Education and Culture Ministry of Republic of Indonesia.

\section{REFERENCES}

[1] Ditjen PP \& PL Kemenkes RI, Statistik Kasus HIV/AIDS di Indonesia Dilapor s/d September 2014,Jakarta: Ditjen PP dan PL Kemenkes RI, 2014.

[2] United Nations Office on Drugs and Crime, Peer to Peer Using Peer to Peer Strategies for Drug Abuse Prevention.New York :United Nations, 2003.

[3] Horizons Project,Peer Education and HIV/AIDS: Past Experience, Future Directions. Birmingham:Population Council, 2007.

[4] A. Giddens, The Constitution of Society: Outline of the Theory of Structuration. East Sussex: Polity Press, 1984.

[5] A.O. Hassan, A.O. Oladeji,K. Osinowo,A.J.Ajuwon,O.P.Atibioke, O.A. Ojomo,B.Ehimatie and O.A. Ladipo,Effects of peer education on AIDS knowledge and sexual behavior among youths on national service and secondary school students in Nigeria International Journal of Public Health and Epidemiology,3 (7), pp. 035-047, 2014.

[6] L. Leonard, I. Ndiaye, A.Kapadia, G.Eisen, O.Diop, S.Mboup and P.Kanki, HIV prevention among Male clients of Female sex worker in Kaolack, Sinegal: result of peer education program. AIDS Education and Prevention, 12, (1), 21, 2000.

[7] K. Ford, D.N.Wirawan, W. Suastina, Evaluation of a peer education Programme for female sex workers in Bali, Indonesia. International Journals of STD \& AIDS, 11, (11), 731, 2000.

[8] D.Van Khoat, G.R. West, R.O. Valdiserri and N.T. Phan, Peer Education for HIV prevention in the Socialist Republic of Vietnam: A National Assessment. Journal of Community Health,28,(1), pp. 1-17, 2003.

[9] K.N. Jozkowski, D.S. Henry and A.A.Sturm, College students' perceptions of the importance of sexual assault prevention education: Suggestions for targeting recruitment for peer-based education. Health Education Journal,74, (1), pp. 4659, 2015.

[10] G. Sriranganathan, D. Jaworsky, J. Larkin,S. Flicker, L. Campbell, S. Flynn, J. Janssen and L. Erlich, Peer sexual health education : Interventions for effective Programme evaluation. Health Education Journal, January, 71,(1),pp. 62-71, 2012.

[11] D. Jaworsky, J. Larkin, G. Sriranganathan, J. Clout, J. Janssen, L. Campbell, S. Flicker, D. Stadnicki, L. Erlich and S. Flynn, Evaluating Youth Sexual Health Peer Education Programs: Challenges and Suggestions for Effective Evaluation Practices.
Journal of Education and Training Studies, 1,(1), pp. 227-234, 2013.

[12] J.M. Frantz, A Peer-Led Approach To Promoting Health Education In Schools: The Views Of Peers. South African Journal of Education,35, (1),pp. 1-7, 2015.

[13] CEDPA, Using Peer Educators to Improve Adolescent Reproductive Health in Ghana, Washington DC: CEDPA

[14] M.B.Miles,A.M.Huberman and J.Saldana, Qualitative Data Analysis: A Methods Sourcebook. California : Sage Publication Inc, 2014.,2002.

[15] S. E. Adamchak, Youth Peer Education in Reproductive Health and HIV/AIDS: Progress, Process, and Programming for the Future. Arlington : Family Health International, 2006. 